MATEC Web of Conferences 3, 01058 (2013)

DOI: $10.1051 /$ matecconf/20130301058

C Owned by the authors, published by EDP Sciences, 2013

\title{
Determination of experimental excess molar properties for mixtures of carboxylic acids
}

\author{
A. Attia ${ }^{1,2}$, F. Mutelet ${ }^{1}$, R. Solimando ${ }^{1}$, M. Jeday ${ }^{2}$, and S. Tretjak ${ }^{3}$ \\ ${ }^{1}$ Laboratoire Réactions et Génie des Procédés LRGP UPR CNRS 3349, Equipe « Thermodynamique et Energie » INPL - \\ ENSIC, 1 rue Grandville, BP 20459, Nancy Cedex, France \\ ${ }^{2}$ Unité de Recherche Energétique et Environnement UR/99, Ecole nationale d'Ingénieurs de Gabes, rue d'Omar El KHattab \\ 6029, Gabès, Tunisie \\ ${ }^{3}$ ARKEMA, CRDE 57501 BP1005 St Avold Cedex, France
}

In separation design, mixture enthalpy data are important not only for determination of heat loads, but also for the design of distillation units. For fitting interaction parameters of $\mathrm{g}^{\mathrm{E}}$, applicable for a larger temperature range, enthalpy of mixing data directly provide the temperature dependence of the activity coefficients. Therefore, a combination of vapor-liquid equilibrium and mostly excess enthalpy measurements is a good solution to cover a broad range of temperature.

In this work, measurement of excess enthalpy for two interesting industrial binary systems acetic acid-acrylic acid $\}$ and $\{$ acetic acid-propanoic acid $\}$ is carried. A standard Calvet calorimeter (C80) was employed to determine the excess molar enthalpies at $298.15 \mathrm{~K}$ and atmospheric pressure of two binary systems. As far as we know, in the literature, no study on experimental data is carried out especially for $\{$ acetic acid-acrylic acid mixtures.

Experimental data were correlated with NRTL-HOC [1, 2] and UNIQUAC-HOC [2, 3] activity coefficient models to obtain the binary interaction parameters. The results lead to a good agreement with the experimental points. Results obtained using excess enthalpies confirm the reliability of the model determined using vapour-liquid [3-5] equilibrium data.

\section{References}

1. H. Renon, J.M. Prausnitz AIChE J. 14135 (1968)

2. J.G. Hayden, J.P. O'Connell, Ind. Eng. Chem. Process Des. DeV. 14209 (1975)

3. D.S. Abrams, J.M Prausnitz. AIChE J. 21116 (1975)

4. J. Linek, I. Wichterle, Collect. Czech. Commun. 38(7) $1853(1973)$

5. S. Trybula, J. Bandrowski, Inz. Chem. 49(6) 1857 (1976) 